University of Nebraska - Lincoln

DigitalCommons@University of Nebraska - Lincoln

U.S. Environmental Protection Agency Papers

U.S. Environmental Protection Agency

2009

Evaluation of alternative approaches for screening contaminated sediments and soils for polychlorinated dibenzo-p-dioxins and polychlorinated dibenzofurans

\author{
Mary Schrock \\ Battelle Memorial Institute, schrock@battelle.org \\ Amy Dindal \\ Battelle Memorial Institute, dindala@battelle.org \\ Stephen Billets \\ U.S. EPA, billets.stephen@epa.gov
}

Follow this and additional works at: https://digitalcommons.unl.edu/usepapapers

Schrock, Mary; Dindal, Amy; and Billets, Stephen, "Evaluation of alternative approaches for screening contaminated sediments and soils for polychlorinated dibenzo-p-dioxins and polychlorinated dibenzofurans" (2009). U.S. Environmental Protection Agency Papers. 177.

https://digitalcommons.unl.edu/usepapapers/177

This Article is brought to you for free and open access by the U.S. Environmental Protection Agency at DigitalCommons@University of Nebraska - Lincoln. It has been accepted for inclusion in U.S. Environmental Protection Agency Papers by an authorized administrator of DigitalCommons@University of Nebraska - Lincoln. 


\title{
Evaluation of alternative approaches for screening contaminated sediments and soils for polychlorinated dibenzo-p-dioxins and polychlorinated dibenzofurans
}

\author{
Mary Schrock $^{\mathrm{a}, *}$, Amy Dindal ${ }^{\mathrm{a}}$, Stephen Billets ${ }^{\mathrm{b}}$ \\ ${ }^{a}$ Battelle Memorial Institute, 505 King Avenue, Columbus, OH 43201, USA \\ ${ }^{\mathrm{b}}$ U.S. EPA, National Exposure Research Laboratory, 944 East Harmon Avenue, Las Vegas, NV 89119, USA
}

\section{A R T I C L E I N F O}

Article history:

Received 21 September 2007

Received in revised form 3 July 2008

Accepted 27 July 2008

Available online 18 September 2008

\section{Keywords:}

EPA Method 1613B

PCDD/F

TEQ

Screening approaches

\begin{abstract}
A B S T R A C T
Traditional high resolution mass spectrometry (HRMS) analysis for polychlorinated dibenzo- $p$-dioxins and polychlorinated dibenzofurans ( $\mathrm{PCDD} / \mathrm{Fs}$ ) can be time consuming and expensive. Consequently, alternative methods are of great interest to regulatory agencies and others characterizing contaminated sites. One factor that hinders acceptance of alternative methods is a lack of performance information that assesses the alternative method's impacts on analytical results. The U.S. Environmental Protection Agency's Superfund Innovative Technology Evaluation Monitoring and Measurement Technologies Program (EPA SITE MMT) encourages the development and implementation of innovative and alternative monitoring methods by providing performance information on site characterization technologies. This paper presents a comparison of the results obtained from laboratory-based alternative approaches for screening sediment and soil samples for dioxin toxicity equivalents $\left(\mathrm{TEQ}_{\mathrm{D} / \mathrm{F}}\right)$ to results obtained using traditional HRMS. The laboratory-based approaches included modifying the traditional HRMS analysis to make it more cost-effective (alternate 1613B), analyzing extracts that had been prepared for HRMS using low resolution mass spectrometry, and determining total organic carbon (TOC) content as an indicator of PCDD/F content. These comparisons demonstrated that $\mathrm{TEQ}_{\mathrm{D} / \mathrm{F}}$ values generated using toxicity equivalency factors proposed by the World Health Organization in 1998 applied to alternate 1613B and LRMS analyses have a strong linear correlation to the $\mathrm{TEQ}_{\mathrm{D} / \mathrm{F}}$ values derived in the same fashion from traditional HRMS analysis. These results would have placed $>90 \%$ of the samples within the same concentration intervals using ranges of $<0.05,0.05-0.50,0.50-5$, and $>5 \mathrm{ng}$ TEQ/g. Natural log transformed data for TOC had significantly weaker correlation to $\mathrm{TEQ}_{\mathrm{D} / \mathrm{F}}$, indicating that TOC is not a reliable indicator of $T E \mathrm{Q}_{\mathrm{D} / \mathrm{F}}$ concentrations.
\end{abstract}

() 2008 Elsevier Ltd. All rights reserved.

\section{Introduction}

Traditional high resolution mass spectrometry (HRMS) methods for analyzing polychlorinated dibenzo-p-dioxins and polychlorinated dibenzofurans (PCDD/Fs) and related compounds involve extensive sample preparation and analysis using complex instrumentation. These traditional methods seek to provide accurate, low pg/g or part-per-trillion level data, but tend to be costly. When using traditional HRMS methods, the number of samples that can be included in contaminated site evaluations is often limited by budget constraints. Consequently, lower-cost alternative methods with known performance attributes are of great interest to regulatory agencies and others involved in characterizing PCDD/ F contaminated sites. In 2004, the U.S. Environmental Protection

\footnotetext{
* Corresponding author. Tel.: +1 614424 4976; fax: +1 6144584976.

E-mail addresses: schrock@battelle.org (M. Schrock), dindala@battelle.org (A. Dindal), billets.stephen@epa.gov (S. Billets).
}

Agency's (EPA's) Superfund Innovative Technology Evaluation (SITE) Monitoring and Measurement Technology (MMT) Program evaluated the efficacy of five bioanalytical technologies in determining PCDD/Fs in soil and sediment during a field demonstration (U.S. EPA, 2004a). PCDD/F results generated by these technologies were compared to results obtained using proven, traditional analytical methods, namely EPA Method 1613, Revision B (U.S. EPA, 1994), a HRMS method for PCDD/Fs that is referred to in this paper as "traditional 1613B". Results of these evaluations, published elsewhere (U.S. EPA, 2005a,b,c,d,e), concluded that these bioanalytical techniques generated results which indicated sediment and soil concentrations were above and below threshold levels, but did not show strong linear correlation to HRMS results. As such, three laboratory-based techniques were evaluated as screening alternatives to $1613 \mathrm{~B}$.

In the first approach, samples were screened using EPA Method $1613 \mathrm{~B}$ with alterations to reduce analysis time and cost (referred to as "alternate 1613B" in this paper). Alterations included using pressurized liquid extraction (PLE) as a faster, more cost-effective 
technique than traditional Soxhlet extraction; bypassing secondcolumn confirmation of 2,3,7,8-tetrachlorodibenzofuran (2,3,7,8TCDF); significantly reducing the quantity of sample extracted from sites known to have high PCDD/F concentrations; and not diluting and reanalyzing samples with $\mathrm{PCDD} / \mathrm{F}$ levels above the calibration range. Data were evaluated to determine if the differences in the alternate 1613B approach affected the resulting sample dioxin toxicity equivalents $\left(\mathrm{TEQ}_{\mathrm{D} / \mathrm{F}}\right)$, cost, and turnaround time. In order to evaluate other lower-cost laboratory-based alternative approaches for PCDD/F screening, extracts generated for the traditional 1613B and alternate 1613B analyses were also analyzed by LRMS, and solid samples were evaluated for total organic carbon (TOC) as an indicator of PCDD/F content. The alternate 1613B, LRMS and TOC evaluations are presented in this paper.

\section{Experimental}

\subsection{Environmental sampling sites}

In selecting sites for inclusion in the SITE program, sample providers were given a guideline concentration range for dioxins of $<0.05-5 \mathrm{ng} / \mathrm{g}$. In addition, so that technologies could be evaluated in the presence of common co-contaminants representative of a diverse range of Superfund sites, samples containing polychlorinated biphenyls (PCBs), pentachlorophenol (PCP), and polynuclear aromatic hydrocarbons (PAHs) were sought. Ten sites, described in Table 1, were selected based on recommendations from a technical advisory panel that included EPA Regional staff, EPA Program Office representatives, and Michigan Department of Environmental Quality (MDEQ) staff. Table 1 also describes the estimated levels (i.e., low, medium, and high) of PCDD/F, PCB, and $\mathrm{PAH}$ contamination at each site, as provided by the sampling team from each site. Up to six discrete samples were collected from various locations within each site. The number of samples from each site which were used in the study is noted in Table 2 .

\subsection{Environmental sample homogenization}

Samples collected from the 10 environmental sites were dried and homogenized according to the procedure described in the SITE demonstration plan (U.S. EPA, 2004a). Although pre-treatment may have resulted in sample compositions that did not necessarily represent the original contaminant concentration, this ensured that sub-samples of a given matrix would have consistent contaminant concentrations. Four replicates of each environmental sample were then analyzed using both the alternate 1613B and traditional 1613B procedures.

\subsection{Traditional $1613 B$ analysis}

All TEQ data in the paper are the total TEQ of $172,3,7,8$-PCDD/Fs using the toxicity equivalency factors (TEFs) proposed by the World Health Organization (van den Berg et al., 1998). Updated TEFs that were published later (van den Berg et al., 2006) were not used because the data were generated prior to their release. All nondetected concentrations were assigned a zero concentration in TEQ calculation.

Approximately $10 \mathrm{~g}$ of each sample were spiked with a suite of ${ }^{13} \mathrm{C}_{12}$-labeled internal standards prior to extraction. Samples were extracted using Soxhlet-Dean Stark apparatus with toluene as the solvent. Extracts were cleaned up through a series of chromatographic columns that included silica, Florisil, carbon/Celite, and alumina columns. Extracts were concentrated to $20 \mu \mathrm{L}$ and spiked with ${ }^{13} \mathrm{C}_{12}$-labeled recovery standards. High resolution gas chromatography (HRGC)/HRMS analysis was performed on either a VG 70 VSE or Micromass Autospec HRMS interfaced to a Hewlett Packard 5890 Series II or 6890 GC with a J\&W Scientific DB-5 [60 meter $(\mathrm{m}) \times 0.25$-mm inside diameter (i.d.) $\times 0.1$-micrometer $(\mu \mathrm{m})$ film thickness] capillary chromatography column. A secondcolumn, J\&W Scientific DB-225 (30 m $\times 0.25-\mathrm{mm}$ i.d. $\times 0.15-\mu \mathrm{m}$ film thickness), was used to confirm 2,3,7,8-TCDF identification. Note that while these HRGC columns vary in i.d. and film thickness from those specified in traditional 1613B, the columns were implemented only after demonstrating acceptable specificity and performance as required by the method. Samples that were known to contain extremely high levels of PCDD/Fs were extracted without adding the internal standard, split, then spiked with the isotopically labeled internal standard prior to cleanup. This approach allowed extraction of the method-specified $10-\mathrm{g}$ sample weight and subsequent sufficient dilution to bring peak areas of high-level analytes within the peak areas generated by the calibration standards. Although this approach introduces some uncertainty because analyte recovery through the extraction process is unknown, the technical advisory panel that guided the project concluded that analyte recoveries with this method are generally acceptable, and the uncertainty introduced by this approach was considered similar to or less than the uncertainty introduced by other approaches, such as extracting a smaller sample size or trying

Table 1

Site descriptions

\begin{tabular}{|c|c|c|}
\hline $\begin{array}{l}\text { Site } \\
\text { no. }\end{array}$ & Location & ite description \\
\hline 1 & $\begin{array}{l}\text { Warren County, North } \\
\text { Carolina }\end{array}$ & $\begin{array}{l}\text { Soil from over } 210 \text { miles of highway shoulders contaminated by illegal spraying of waste transformer oil containing PCBs. Some areas have } \\
\text { very high PCDD/F, PCB and PAH levels }\end{array}$ \\
\hline 2 & $\begin{array}{l}\text { Tittabawassee River, } \\
\text { Michigan }\end{array}$ & $\begin{array}{l}\text { Flood plain soils from several different locations along the river. Speculated legacy contamination from chemical manufacturing. Low PCB and } \\
\text { PAH, low to mid-level PCDD/F }\end{array}$ \\
\hline 3 & Newark Bay, New Jersey & $\begin{array}{l}\text { Sediment from areas contaminated from numerous sources. This bay is downstream from a dioxin Superfund site. Low PCB and PAH, low to } \\
\text { mid-level PCDD/F }\end{array}$ \\
\hline 4 & Raritan Bay, New Jersey & Sediments from areas surrounded by industrial and residential discharges. Low-level PCB, PAH, and PCDD/F \\
\hline 5 & Winona, Missouri & $\begin{array}{l}\text { Soil from a wood treatment facility Superfund site. Contaminants at the site included pentachlorophenol, dioxins, diesel fuel, and PAHs. High- } \\
\text { level PCDD/F, medium level PAH, low to mid-level PCBs }\end{array}$ \\
\hline 6 & $\begin{array}{l}\text { Tittabawassee River, } \\
\text { Michigan }\end{array}$ & $\begin{array}{l}\text { Sediments from areas around Midland and Saginaw County. Speculated legacy contamination from chemical manufacturing. Low to mid- } \\
\text { level PCDD/F, low PCB and PAH }\end{array}$ \\
\hline 7 & Brunswick, Georgia & $\begin{array}{l}\text { Sediments from the Brunswick Wood Preserving Superfund site. This site had pentachlorophenol, creosote, and chromium copper arsenic } \\
\text { wood treating operations from } 1960 \text { until early 1991. Low to high-level PCDD/F and PAH, low-level PCB }\end{array}$ \\
\hline 8 & Saginaw River, Michigan & $\begin{array}{l}\text { Flood plain sediments. Speculated legacy contamination from chemical manufacturing. Mid to high-level PCDD/F, low to mid-level PCB, low- } \\
\text { high- level PAH }\end{array}$ \\
\hline 9 & Midland, Michigan & $\begin{array}{l}\text { Soils from Midland residential areas. Speculated legacy contamination from chemical manufacturing. Low to mid-level PCDD/F, low-level PCB } \\
\text { and PAH }\end{array}$ \\
\hline 10 & Nitro, West Virginia & Agent Orange was manufactured at this site from 1948 to 1969. Soils expected to have low to high levels of PCDD/F, low-level PCB and PAH \\
\hline
\end{tabular}


Table 2

Summary of results by site: HRMS, LRMS, and TOC

\begin{tabular}{|c|c|c|c|c|c|c|}
\hline \multirow[t]{3}{*}{ Site no. } & \multirow[t]{3}{*}{ Sample no. } & \multicolumn{4}{|c|}{ Average total $\mathrm{TEQ}_{\mathrm{D} / \mathrm{F}}(\mathrm{ng} / \mathrm{g})^{\mathrm{a}}$} & \multirow[t]{3}{*}{ TOC (\%) } \\
\hline & & \multicolumn{2}{|l|}{ Alternate 1613B } & \multicolumn{2}{|l|}{ Traditional 1613B } & \\
\hline & & HRMS & LRMS & HRMS & LRMS & \\
\hline \multirow[t]{5}{*}{$\overline{1}$} & 1 & $0.27 \pm 0.03$ & $0.37 \pm 0.03$ & $0.9 \pm 0.1$ & $1.1 \pm 0.1$ & 1.40 \\
\hline & 2 & $5.1 \pm 0.4$ & $5.5 \pm 0.3$ & $3.41 \pm 0.08$ & $4.1 \pm 0.1$ & - \\
\hline & 3 & $11.8 \pm 0.4$ & - & $9 \pm 1$ & - & - \\
\hline & 4 & $16.2 \pm 0.5$ & - & - & - & 2.38 \\
\hline & 5 & $13.7 \pm 0.3$ & - & - & - & 5.26 \\
\hline \multirow[t]{6}{*}{2} & 1 & $0.04 \pm 0.01$ & $0.05 \pm 0.01$ & $0.037 \pm 0.002$ & $0.030 \pm 0.003$ & 1.63 \\
\hline & 2 & $0.44 \pm 0.02$ & $0.57 \pm 0.03$ & $0.47 \pm 0.05$ & $0.43 \pm 0.03$ & 2.11 \\
\hline & 3 & $0.81 \pm 0.08$ & $1.1 \pm 0.2$ & $1.1 \pm 0.3$ & $1.0 \pm 0.2$ & 1.49 \\
\hline & 4 & $3.1 \pm 0.2$ & - & - & - & 4.28 \\
\hline & 5 & $1.1 \pm 0.2$ & - & - & - & 1.60 \\
\hline & 6 & $1.2 \pm 0.8$ & - & - & - & 0.66 \\
\hline \multirow[t]{6}{*}{3} & 1 & $0.016 \pm 0.004$ & $0.015 \pm 0.008$ & $0.016 \pm 0.005$ & $0.015 \pm 0.003$ & 0.49 \\
\hline & 2 & $0.062 \pm 0.009$ & $0.09 \pm 0.04$ & $0.06 \pm 0.01$ & $0.06 \pm 0.01$ & 1.64 \\
\hline & 3 & $0.05 \pm 0.01$ & - & $0.042 \pm 0.003$ & - & - \\
\hline & 4 & $0.032 \pm 0.002$ & $0.041 \pm 0.005$ & $0.029 \pm 0.003$ & $0.031 \pm 0.004$ & 1.01 \\
\hline & 5 & $0.038 \pm 0.004$ & - & - & - & 1.01 \\
\hline & 6 & $0.02 \pm 0.02$ & - & - & - & 0.27 \\
\hline \multirow[t]{6}{*}{4} & 1 & $0.012 \pm 0.001$ & $0.0113 \pm 0.0003$ & $0.0106 \pm 0.0006$ & $0.0066 \pm 0.0003$ & 6.37 \\
\hline & 2 & $0.014 \pm 0.001$ & - & $0.0128 \pm 0.0002$ & - & 2.67 \\
\hline & 3 & $0.012 \pm 0.001$ & - & $0.0105 \pm 0.0005$ & - & 2.23 \\
\hline & 4 & $0.014 \pm 0.001$ & - & - & - & 2.73 \\
\hline & 5 & $0.012 \pm 0.001$ & - & - & - & 2.64 \\
\hline & 6 & $0.015 \pm 0.002$ & - & - & - & 2.64 \\
\hline \multirow[t]{4}{*}{5} & 1 & $8.83 \pm 0.06$ & $11.6 \pm 0.1$ & $7.3 \pm 0.1$ & $7.2 \pm 0.3$ & 7.56 \\
\hline & 2 & $11.1 \pm 0.2$ & $13.1 \pm 0.6$ & $10.0 \pm 0.9$ & $9.7 \pm 0.9$ & 7.63 \\
\hline & 3 & $11.7 \pm 0.2$ & - & $9.8 \pm 0.4$ & - & 8.05 \\
\hline & 4 & $11.3 \pm 0.5$ & - & - & - & 9.42 \\
\hline \multirow[t]{6}{*}{6} & 1 & $0.0011 \pm 0.0003$ & $0.0008 \pm 0.0005$ & $0.0012 \pm 0.0003$ & $0.0005 \pm 0.0002$ & 0.40 \\
\hline & 2 & $0.055 \pm 0.004$ & $0.070 \pm 0.005$ & $0.08 \pm 0.03$ & $0.07 \pm 0.03$ & 0.31 \\
\hline & 3 & $0.016 \pm 0.004$ & - & $0.013 \pm 0.001$ & - & 0.12 \\
\hline & 4 & $0.2 \pm 0.2$ & - & - & - & 0.27 \\
\hline & 5 & $0.2 \pm 0.3$ & - & - & - & 0.17 \\
\hline & 6 & $0.6 \pm 0.3$ & - & - & - & 1.17 \\
\hline \multirow[t]{3}{*}{7} & 1 & $0.069 \pm 0.006$ & $0.08 \pm 0.02$ & $0.067 \pm 0.004$ & $0.063 \pm 0.004$ & 0.88 \\
\hline & 2 & $0.065 \pm 0.001$ & - & $0.06 \pm 0.01$ & - & 1.27 \\
\hline & 3 & $16.1 \pm 0.8$ & - & $14 \pm 1$ & - & 1.43 \\
\hline \multirow[t]{3}{*}{8} & 1 & $0.92 \pm 0.08$ & $1.20 \pm 0.09$ & $0.9 \pm 0.2$ & $0.9 \pm 0.3$ & 4.54 \\
\hline & 2 & $1.1 \pm 0.3$ & $1.4 \pm 0.4$ & $1.1 \pm 0.2$ & $1.1 \pm 0.2$ & 4.20 \\
\hline & 3 & $0.20 \pm 0.07$ & $0.28 \pm 0.09$ & $0.12 \pm 0.02$ & $0.12 \pm 0.02$ & 6.58 \\
\hline \multirow[t]{4}{*}{9} & 1 & $0.24 \pm 0.01$ & $0.30 \pm 0.07$ & $0.25 \pm 0.02$ & $0.271 \pm 0.009$ & 6.71 \\
\hline & 2 & $0.184 \pm 0.009$ & $0.26 \pm 0.02$ & $0.19 \pm 0.01$ & $0.21 \pm 0.02$ & 3.12 \\
\hline & 3 & $0.15 \pm 0.01$ & - & $0.17 \pm 0.01$ & - & 5.09 \\
\hline & 4 & $0.025 \pm 0.002$ & $0.035 \pm 0.004$ & $0.027 \pm 0.003$ & $0.025 \pm 0.001$ & 2.92 \\
\hline \multirow[t]{6}{*}{10} & 1 & $0.048 \pm 0.005$ & - & $0.065 \pm 0.009$ & - & 1.45 \\
\hline & 2 & $1.8 \pm 0.4$ & $2.1 \pm 0.4$ & $2.0 \pm 0.1$ & $2.1 \pm 0.1$ & 4.51 \\
\hline & 3 & $3.3 \pm 0.4$ & $4.3 \pm 0.5$ & $2.9 \pm 0.1$ & $2.9 \pm 0.2$ & \\
\hline & 4 & $0.9 \pm 0.2$ & - & - & - & 1.34 \\
\hline & 5 & $1.3 \pm 0.1$ & - & - & - & 13.52 \\
\hline & 6 & $4.0 \pm 0.2$ & - & - & - & 2.06 \\
\hline
\end{tabular}

“_” Data not available.

a Average results generated from analyses of four replicate samples.

to anticipate sample concentrations to allow spiking with larger amounts of internal standard and concentrating to a larger sample volume.

\subsection{Alternate $1613 B$ screening}

Depending on the PCDD/F level estimates provided by samplers from each sampling location, approximately $1-10 \mathrm{~g}$ aliquots of sediment or soil were weighed for extraction, spiked with ${ }^{13} \mathrm{C}_{12^{-}}$ labeled internal standards, and extracted with methylene chloride using a Dionex ASE 200 Accelerated Solvent Extraction system (ASE). Extractions were carried out at $13.8 \mathrm{MPa}(2000 \mathrm{psi}), 125^{\circ} \mathrm{C}$, and three static cycles of $10 \mathrm{~min}$ each. The sample extracts were processed through various cleanup techniques which included gel permeation chromatography or acid/base washes, as well as acid/ base silica and carbon cleanup columns. These cleanup procedures 
followed general procedures described in EPA Method 1613, Revision B (U.S. EPA, 1994). As warranted based on sample compositions, some samples were put through additional acid silica cleanup prior to the carbon column cleanup. Extracts were spiked with ${ }^{13} \mathrm{C}_{12}$-labeled recovery standards and concentrated to a final volume of 20-50 $\mu \mathrm{L}$. Each extract was analyzed by HRGC/HRMS (VG Autospec or Autospec Ultima) in the selected ion monitoring mode at a resolution of 10,000 or greater. A Phenomenex ZB-5 ( $60 \mathrm{~m} \times 0.32-\mathrm{mm}$ i.d. $\times 0.25-\mu \mathrm{m}$ film thickness) capillary chromatography column was used to analyze the $172,3,7,8$-substituted PCDD/F congeners. Note that when using a ZB-5 column, 2,3,7,8TCDF is not separated from non-2,3,7,8-TCDF isomers; therefore, lack of separation of 2,3,7,8-TCDF from other isomers could overestimate a sample's dioxin-like toxicity. However, since the primary objective was to screen for dioxin-like toxicity, 2,3,7,8-TCDF was not confirmed on a second-column. Extracts were diluted and reanalyzed if high levels of a particular congener were observed in the initial analysis; however, extracts were not rigorously evaluated to ensure that all peaks were below the peak area of the highest calibration standard.

\subsection{Low resolution mass spectrometry analysis}

A subset of the extracts archived after use in the traditional 1613B and alternate 1613B analyses (described in Sections 2.3 and 2.4) was analyzed by LRMS for comparison to the HRMS results. While LRMS is less sensitive and less selective than HRMS, LRMS combined with the extensive sample preparation of the traditional HRMS analysis, offers the possibility of a less expensive analysis while still providing individual congener data to generate TEQ results for screening purposes. SW-846 Method 8280A (U.S. EPA, 1996) exists as an LRMS method for PCDD/F for determining ng/g (part-per-billion) concentration levels. The approach taken for this study did not follow Method 8280A, but rather focused on lower concentrations by using the same sample preparation and instrument calibration solutions as for EPA Method 1613B, only substituting LRMS analysis for HRMS. The LRMS method implemented here was capable of detecting the lowest calibration point of EPA Method 1613B which was $0.5 \mathrm{ng} / \mathrm{mL}$ for tetra-chlorinated compounds, $2.5 \mathrm{ng} / \mathrm{mL}$ for penta-hepta-chlorinated compounds, and $5 \mathrm{ng} / \mathrm{mL}$ for octa-chlorinated compounds. Based on a $10 \mathrm{~g}$ sample and $20 \mu \mathrm{L}$ final volume this corresponds to sample concentrations of 1,5 , and $10 \mathrm{pg} / \mathrm{g}$, respectively. Therefore, this method demonstrated the detection of ppt levels of PCDD/F when samples were sufficiently cleaned.

LRMS analysis was performed using a Hewlett Packard 6890 GC interfaced to a $5973 \mathrm{~N}$ Mass Selective Detector. Separation was achieved with a Phenomenex ZB-5 $(60 \mathrm{~m} \times 0.32-\mathrm{mm}$ i.d. $\times 0.25-\mu \mathrm{m}$ film thickness) column using the same temperature program as used for the alternate 1613B analysis. Chromatograms generated by LRMS were quantified using the same identification and quantification criteria as for traditional 1613B. A continuing calibration standard (Cambridge Isotope Laboratories, CIL, EDF-9999-3) and column performance check standard (CIL ED-908) were analyzed after every 10 samples. The goal for column performance was $25 \%$ valley between 2,3,7,8-TCDD and its closest eluting isomer, but a $45 \%$ valley was achieved at best. Continuing calibration criteria followed traditional 1613B requirements.

\subsection{Total organic carbon}

The affinity of PCDD/Fs to bind to organic carbon suggests that PCDD/F levels in soil may correlate with TOC levels in soil. A strong correlation has been observed at some sites, provided the PCDD/F content did not exceed the soil's sorption capacity (Brzuzy and Hites, 1995). To investigate whether TOC could be used to predict
TEQ $_{D / F}$ values, samples were analyzed by Applied Marine Sciences, Inc. (AMS, League City, TX) for TOC using SW-846 Method 9060A (U.S. EPA, 2004b). Method 9060A uses a carbonaceous analyzer to convert organic carbon into carbon dioxide. The method involves adjusting the sample $\mathrm{pH}$ to 2 , purging the sample with nitrogen, and analyzing the sample in quadruplicate. Twenty-five grams of each sample were sent to AMS for analysis. The samples were processed in batches of 15 or less. Quality control samples prepared with each batch included a duplicate and a method blank. TOC results were compared to $\mathrm{TEQ}_{\mathrm{D} / \mathrm{F}}$ values generated by traditional 1613B and alternate 1613B.

\section{Discussion}

Table 2 presents the average total TEQD/F concentration from the quadruplicate alternate $1613 \mathrm{~B}$ and quadruplicate traditional 1613B analyses, along with the average total $\mathrm{TEQ}_{\mathrm{D} / \mathrm{F}}$ concentration from quadruplicate LRMS analyses for a subset of the extracts. The average total $\mathrm{TEQ}_{\mathrm{D} / \mathrm{F}}$ data from the alternate $1613 \mathrm{~B}$ analyses were plotted against the data from the traditional 1613B analyses for 32 environmental samples presented in Table 2. As shown in Table 3 there is a high correlation between the alternate 1613B and traditional $1613 \mathrm{~B}$ results $\left(R^{2}=0.99\right.$, slope $\left.=1.20\right)$. The overall average relative standard deviation (RSD) for the alternate 1613B method was $11 \%$, while the average RSD for traditional $1613 \mathrm{~B}$ was $12 \%$. A paired $t$-test comparing the alternate 1613B RSD to the traditional 1613B RSD for each sample verified that the precision of the alternate 1613B method was not significantly different from that of traditional 1613B based on a $p$-value of 0.5884 , when the criteria used for statistical significance was $p$-values less than 0.05 . To assess comparability, the mean and median relative percent

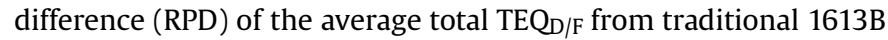
and alternate $1613 \mathrm{~B}$ were determined. A mean RPD of $18 \%$ and median RPD of $11 \%$ indicate that the data from alternate $1613 \mathrm{~B}$ were comparable to the data generated from the traditional 1613B.

As another measure of comparability, the alternate and traditional 1613B data were grouped into four TEQ concentration intervals. The interval ranges were $<0.05,0.05-0.50,0.50-5$, and $>5 \mathrm{ng}$ TEQ/g. The intervals were determined by the technical advisory panel and are the same intervals that were used to assess the five bioanalytical technologies that were a part of the SITE demonstration. Using these intervals, $90 \%$ of the samples (all but three) fell into the same decision category using either the traditional or alternate 1613B approach. The exceptions are Warren County, North Carolina (Site 1) sample 1; Newark Bay, New Jersey

\section{Table 3}

Correlations between screening approaches and traditional $1613 \mathrm{~B}$ generated TEQ $\mathrm{D} / \mathrm{F}$

\begin{tabular}{|c|c|c|c|c|}
\hline \multicolumn{2}{|l|}{$\begin{array}{l}\text { Correlation conditions between screening approach TEQ }{ }_{D / F} R^{2} \\
\text { and traditional 1613B TEQ }\end{array}$} & \multicolumn{3}{|c|}{ Slope Intercept $n$} \\
\hline Alternate $1613 \mathrm{~B}$ TEQ $\mathrm{D} / \mathrm{F}$ versus traditional $1613 \mathrm{~B}$ TEQ $\mathrm{D} / \mathrm{F}$ & 0.99 & 1.20 & -0.061 & 32 \\
\hline $\begin{array}{l}\text { Relative percent difference (RPD) }>50 \% \text { between } \\
\text { traditional 1613B } 2,3,7,8-\mathrm{TCDF} \text { value without } \\
\text { confirmation and } 2,3,7,8-\mathrm{TCDF} \text { value from second- } \\
\text { column confirmation }\end{array}$ & 1.00 & 0.91 & 0.005 & 9 \\
\hline $\begin{array}{l}\text { RPD }<50 \% \text { between traditional } 1613 \mathrm{~B} 2,3,7,8-\mathrm{TCDF} \text { value } \\
\text { without confirmation and } 2,3,7,8-\mathrm{TCDF} \text { value from } \\
\text { second-column confirmation }\end{array}$ & 0.99 & 1.20 & -0.055 & 23 \\
\hline Alternate $1613 \mathrm{~B}$ extraction of $5 \mathrm{~g}$ or less & 0.99 & 1.20 & -0.057 & 10 \\
\hline Alternate $1613 \mathrm{~B}$ extraction of more than $5 \mathrm{~g}$ & 0.98 & 1.03 & -0.015 & 22 \\
\hline Total TEQ $\mathrm{D} / \mathrm{F}_{\mathrm{F}}$ when no congeners exceeded calibration & 0.95 & 1.00 & -0.039 & 19 \\
\hline $\begin{array}{l}\text { Total } \mathrm{TEQ}_{\mathrm{D} / \mathrm{F}} \text { when one or more congeners exceeded } \\
\text { calibration }\end{array}$ & 0.99 & 1.19 & 0.054 & 13 \\
\hline LRMS analysis of traditional $1613 \mathrm{~B}$ extracts & 0.99 & 0.99 & 0.043 & 22 \\
\hline LRMS analysis of alternate $1613 \mathrm{~B}$ extracts & 0.99 & 1.22 & 0.018 & 22 \\
\hline TOC versus traditional $1613 \mathrm{~B}$ TEQ $\mathrm{D}_{\mathrm{D} / \mathrm{F}}$ & 0.30 & 1.25 & 0.004 & 28 \\
\hline TOC versus alternate $1613 \mathrm{~B} T E Q_{D / F}$ & 0.22 & 1.03 & 0.005 & 32 \\
\hline
\end{tabular}


(Site 3) sample 3; and Nitro, West Virginia (Site 10) sample 1. For the Newark Bay and Nitro samples, values that fell into a different interval were very close to an interval cut-off value (i.e., Newark Bay sample 3 had an alternate 1613B TEQD/F of $0.05 \mathrm{ng} / \mathrm{g}$ and a traditional 1613B TEQ $/ \mathrm{F}$ of $0.042 \mathrm{ng} / \mathrm{g}$, placing this sample in different intervals based on an interval cut-off at $0.05 \mathrm{ng}$ TEQ/g). The North Carolina sample, with an alternate $1613 \mathrm{~B}$ TEQD/F of $0.27 \mathrm{ng} / \mathrm{g}$ and a traditional $1613 \mathrm{~B}$ TEQ $/ \mathrm{F}$ of $0.9 \mathrm{ng} / \mathrm{g}$ had a large enough difference in concentration and resulting TEQ with the two approaches that it fell into different decision categories.

\subsection{Effect of extraction technique: PLE versus Soxhlet}

For solid samples such as sediments and soils, traditional 1613B calls for Soxhlet-Dean Stark extraction with toluene. The alternate 1613B used PLE with methylene chloride as the solvent. PLE is becoming widely demonstrated as an acceptable alternative to Soxhlet extraction (Robinson et al., 2004; Sporring et al., 2003; Li et al., 2003; Misita et al., 2003; Hölscher et al., 2004; Kitamura et al., 2004). PLE's advantages include significant decreases in extraction time and solvent usage. Because modifications to traditional 1613B which improve separation or lower measurement cost are acceptable provided all performance specifications are met (U.S. EPA, 1994), PLE was incorporated after demonstrating acceptable performance on the traditional 1613B required initial precision and recovery sample set. As demonstrated by the good correlation between total $\mathrm{TEQ}_{\mathrm{D} / \mathrm{F}}$ using both extraction approaches (see Table 3), results generated using PLE exhibited a strong linear relationship to results generated using Soxhlet extraction.

\subsection{Effect of second-column confirmation}

2,3,7,8-TCDF is not completely resolved from all other tetrafuran isomers with a DB-5 or ZB-5 capillary column; therefore, 2,3,7,8TCDF results based on this column alone may be biased high. However, 2,3,7,8-TCDF can be separated from the other tetrafurans by analyzing the sample extract on a second column of different polarity (e.g., DB-225). This second-column confirmation analysis requires over 30 min of additional analysis time per sample, as well as additional labor hours for data reduction and reporting. While the exact determination of 2,3,7,8-TCDF can be important for regulatory purposes, on a TEQ basis, the importance of 2,3,7,8-TCDF is minimized due to its 1998 WHO TEF of 0.1. Second-column confirmation may be more important in sites where the amount of 2,3,7,8-TCDF varies considerably relative to other co-eluting tetrafurans. To assess the impact of the second-column confirmation, instances where the traditional 1613B results showed a significant reduction in 2,3,7,8-TCDF concentration between the initial (DB-5) and confirmation (DB-225) analyses were compared to instances where traditional 1613B results did not show a significant reduction in 2,3,7,8-TCDF concentration between the initial and confirmation analyses. As shown in Table 3 , an $R^{2}$ value of 1.00 was obtained when the difference between the DB-5 initial values for 2,3,7,8TCDF and the DB-225 confirmation values was large (>50\% RPD). This does not significantly differ from the $R^{2}$ value of 0.99 obtained when the difference between the DB-5 initial and DB-225 confirmation 2,3,7,8-TCDF values was smaller ( $<50 \% \mathrm{RPD})$. It should be noted that for the 10 sites evaluated in this study, the TCDF contribution to total TEQ was $<40 \%$ for all sites and $<10 \%$ in six of the 10 sites. Additionally, the RPD in 2,3,7,8-TCDF concentration before and after confirmation was $<50 \%$ in 23 out of the 32 samples. These results show that bypassing $2,3,7,8-\mathrm{TCDF}$ confirmation using alternate $1613 \mathrm{~B}$ did not significantly impact correlation to traditional $1613 \mathrm{~B}$ total $\mathrm{TEQ}_{\mathrm{D} / \mathrm{F}}$ results for samples with TCDF contributions to TEQ as indicated above. Therefore, for total $\mathrm{TEQ}_{\mathrm{D} / \mathrm{F}}$ screening purposes, 2,3,7,8-TCDF second-column confirmation might be considered for alteration as a cost-saving change if program requirements allow, particularly if the TCDF contribution to total TEQ does not exceed $40 \%$ and the RPD between initial and confirm $2,3,7,8-\mathrm{TCDF}$ values is $<50 \%$. Alterations could include eliminating the 2,3,7,8-TCDF confirmation requirement with the DB-5 column or using, without confirmation, alternative analytical columns (such as a DB-5MS or Rtx-Dioxin2) that separate 2,3,7,8TCDF from other tetrafuran isomers somewhat better than the DB-5 column required for traditional 1613B (Robinson et al., 2004; Fraisse et al., 1994; Abad et al., 1997).

\subsection{Effect of extracting less than $10 \mathrm{~g}$ of solids}

Traditional 1613B requires the extraction of $10 \mathrm{~g}$ of solids. For samples with known high target analyte concentrations or known interferences (such as might be encountered in a contaminated site), analytical problems such as analyte concentrations above calibration range and chromatographic issues due to interferences can be anticipated. A common alternative is to extract a $10 \mathrm{~g}$ aliquot, then perform a dilution on the extract prior to cleanup and analysis. However, because the samples were well homogenized prior to extraction, a smaller sample aliquot was extracted for alternate 1613B analysis rather than diluting $10 \mathrm{~g}$ extracts in order to minimize equipment contamination. Extracting $<10 \mathrm{~g}$ risks not having a sample representative of the bulk material; therefore, sample homogeneity should be taken into account when considering this modification. To assess the effect of smaller sample size, the total $T E Q_{D / F}$ values between traditional $1613 \mathrm{~B}$ and alternate 1613B were compared between samples where $<5 \mathrm{~g}$ was extracted using alternate $1613 \mathrm{~B}$ to those where $>5 \mathrm{~g}$ was extracted. Overall, the correlation to traditional $1613 \mathrm{~B}$ results where $<5 \mathrm{~g}$ was extracted $\left(R^{2}=0.99\right.$, slope $\left.=1.20\right)$ to instances when $>5 \mathrm{~g}$ was extracted $\left(R^{2}=0.98\right.$, slope $\left.=1.03\right)$ were similar. Correlation results are presented in Table 3.

\subsection{Use of estimated data when calibration range was exceeded}

Traditional 1613B states that if sample peak areas exceed the peak areas obtained during calibration, a smaller aliquot should be analyzed or the sample should be diluted. This requires complete reprocessing of a second, smaller aliquot of sample or a dilution of the sample and a second analysis - both options that increase analysis, instrument operator, and data processing time to work up a second data set. While data that exceed the calibration may be biased high or low, the impact of this often is reduced in conversion to TEQ. Exceptions to this include samples dominated by the presence of 2,3,7,8-TCDD and 1,2,3,7,8-PeCDD, which have TEFs equal to one, and samples with very large quantities of a particular congener where, in spite of having a low TEF, the congener contributes significantly to TEQ due to quantity. In instances such as these, the use of estimated data should be carefully assessed. It should also be noted that for this study, 1998 WHO TEFs (van den Berg et al., 1998) were used. Use of other TEF conventions such as the International Toxicity Equivalency Factors (I/TEF) (NATO CCMS, 1988) can influence how significant the contribution of individual congeners is to the total TEQ. Using the Center for Disease Control's Agency for Toxic Substance Disease Registry (ATSDR) cleanup guidelines (De Rosa et al., 1997), sites with TEQ levels between 0.05 and $1 \mathrm{ng} / \mathrm{g}$ should be further evaluated and action is recommended for levels $>1 \mathrm{ng}$ TEQ/g. The traditional 1613B upper calibration limit based on a $10-\mathrm{g}$ extraction and $20-\mu \mathrm{L}$ final sample volume is $0.4 \mathrm{ng} /$ $\mathrm{g}$ for tetra-chlorinated congeners, $2 \mathrm{ng} / \mathrm{g}$ for penta- through heptachlorinated congeners, and $4 \mathrm{ng} / \mathrm{g}$ for octa-chlorinated congeners. When the concentrations are converted to TEQ all samples with tetra- and penta-chlorinated congeners at concentrations above calibration will have resulting TEQs which will be well above the 


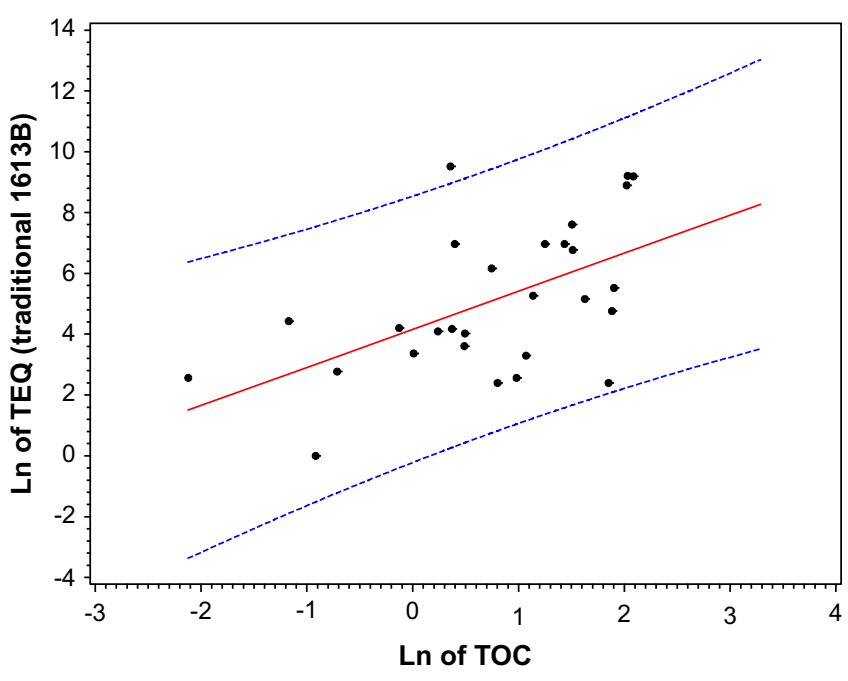

Fig. 1. Natural log transformed TOC results versus natural log transformed traditional $1613 \mathrm{~B}$ results $\left(y=1.25 x+4.16, R_{2}=0.30\right)$.

"further evaluation" category of $0.05 \mathrm{ng}$ TEQ/g. To assess the effect of using estimated data when the calibration range was exceeded, the correlations of traditional 1613B and alternate $1613 \mathrm{~B}$ total $\mathrm{TEQ} \mathrm{Q}_{\mathrm{D} / \mathrm{F}}$ were compared for those instances where some congeners were above the calibration range to those instances where all congeners were within the calibration range (see Table 3). For the samples evaluated in this study, the octa-chlorinated dioxin and furan congeners (OCDD and OCDF) were the primary congeners found above the calibration level. For both OCDD and OCDF, the actual concentration determined by the traditional 1613B approach of diluting and reanalyzing sample extracts was generally larger than that obtained using the alternate $1613 \mathrm{~B}$ approach. This is primarily due to chromatographic peaks approaching instrument saturation with the alternate 1613B approach where no dilution took place, resulting in an underestimation in peak area and consequently an underestimation in concentration. However, upon conversion to total $\mathrm{TEQ}_{\mathrm{D} / \mathrm{F}}$, the congeners above the calibration range had little impact; and overall there was good agreement between the total $\mathrm{TEQ}_{\mathrm{D} / \mathrm{F}}$ regardless of whether there were sample peak areas above the calibration peak areas. In these instances, the congeners above the calibration level were not the primary drivers of TEQ $\mathrm{D} / \mathrm{F}$. Decisions about using estimated data when the calibration range is exceeded should take into consideration the percent contribution to total $\mathrm{TEQ}_{\mathrm{D} / \mathrm{F}}$ that congeners exceeding the calibration range contribute.

\subsection{LRMS analysis}

The TEQ ${ }_{D / F}$ generated by LRMS analysis of 22 extracts that had been prepared for traditional 1613B analysis and 22 extracts that had been prepared for alternate 1613B analysis were compared to their corresponding traditional 1613B or alternate 1613B HRMS $\mathrm{TEQ}_{\mathrm{D} / \mathrm{F}}$ result. Correlation statistics are included in Table 3. The correlation between the LRMS TEQD/F and the HRMS TEQ $\mathrm{D} / \mathrm{F}$ was high $\left(R^{2}=0.99\right.$, slope $=1.22$ for alternate $1613 \mathrm{~B}$ extracts and $R^{2}=0.99$, slope $=0.99$ for traditional $1613 \mathrm{~B}$ extracts). Comparability was also assessed with the interval approach using the same interval ranges used to evaluate the bioanalytical technologies in the SITE reports, and alternate 1613B to traditional 1613B as discussed in the beginning of Section 3 above. Using these intervals $(<0.05,0.05-0.50,0.50-5$, and $>5 \mathrm{ng} \mathrm{TEQ} / \mathrm{g})$, the LRMS analysis of $90 \%$ of the alternate $1613 \mathrm{~B}$ extracts (all but two) and $100 \%$ of the traditional 1613B extracts fell into the same concentration interval as the corresponding HRMS analysis. All values that fell into a different interval were very close to an interval cut-off value (i.e., Tittabawassee River soil number one had an alternate $1613 \mathrm{~B}$ TEQ $\mathrm{D} / \mathrm{F}$ of $0.04 \mathrm{ng} / \mathrm{g}$ and an LRMS TEQ/F of $0.05 \mathrm{ng} / \mathrm{g}$, placing this sample in different intervals based on an interval cut-off at $0.05 \mathrm{ng}$ TEQ/g). In addition to correlating well to HRMS results, LRMS combined with extensive sample cleanup provides significant cost reduction due to using less expensive analytical instrumentation. LRMS also provides individual congener information, which is lost with many other screening techniques.

\subsection{TOC determination}

The correlation between TOC and TEQD/F was evaluated by plotting the TOC results against $\mathrm{TEQ}_{\mathrm{D} / \mathrm{F}}$ values determined using both traditional 1613B and alternate 1613B. Both the TOC and TEQD/F data were natural $\log$ transformed in order to put the data on a more even scale. Fig. 1 shows that there is a linear relationship between the natural log of the TOC values and natural log of the TEQ $_{D / F}$ values; however, with $R^{2}$ values of 0.30 when plotted against the traditional $1613 \mathrm{~B} T E \mathrm{~T}_{\mathrm{D} / \mathrm{F}}$ and 0.22 against the alternate $1613 \mathrm{~B}$ $\mathrm{TEQ}_{\mathrm{D} / \mathrm{F}}$ (correlation statistics are included in Table 3 ) the relationship is not particularly strong. Additionally, the large span for the $95 \%$ confidence levels for the TOC versus $\mathrm{TEQ}_{\mathrm{D} / \mathrm{F}}$ relationship indicates that TOC is not a reliable indicator of TEQ $\mathrm{D} / \mathrm{F}$.

\subsection{Effect of various screening options on cost and sample turnaround time}

Specific differences between traditional 1613B, alternate 1613B, LRMS analysis, and TOC and their impact on analysis time and cost are summarized in Table 4. This table demonstrates that there are savings in labor hours, materials, and instrument usage with the various laboratory-based screening approaches which could result in a cost-savings of hundreds of dollars per sample compared to the cost of traditional 1613B analysis. In addition, depending on the approach, extraction or analysis time can be significantly reduced

Table 4

Impact of screening modifications to cost and turnaround time

\begin{tabular}{|c|c|c|}
\hline Traditional 1613B analysis & Screening modification & Impact of modification \\
\hline Soxhlet-Dean Stark extraction with toluene & ASE with methylene chloride & $\begin{array}{l}\text { For a batch of } 20 \text { samples, ASE is estimated to save approximately } 6 \text { labor hours } \\
\text { and } 7 \mathrm{~L} \text { of solvent }\end{array}$ \\
\hline 2,3,7,8-TCDF concentrations confirmed & $\begin{array}{l}\text { 2,3,7,8-TCDF concentrations not } \\
\text { confirmed }\end{array}$ & $\begin{array}{l}\text { Second-column confirmation of } 2,3,7,8-\mathrm{TCDF} \text { adds over } 30 \text { min of analysis time } \\
\text { per sample plus additional labor hours in data reduction and reporting }\end{array}$ \\
\hline $\begin{array}{l}10 \mathrm{~g} \text { always extracted (high concentration sites were } \\
\text { extracted and then diluted before adding internal } \\
\text { standard) }\end{array}$ & $\begin{array}{l}1-10 \mathrm{~g} \text { was used depending on } \\
\text { what was known about the site }\end{array}$ & $\begin{array}{l}\text { Fewer dilutions were needed using the } 1-10 \mathrm{~g} \text { extraction approach resulting in } \\
\text { decreased analysis time and fewer repeated analyses }\end{array}$ \\
\hline $\begin{array}{l}\text { All samples were diluted so that sample peak areas were } \\
\text { within the range of calibration standard peak areas }\end{array}$ & $\begin{array}{l}\text { Used estimated data if } \\
\text { calibration range was exceeded. }\end{array}$ & $\begin{array}{l}\text { Fewer dilutions were needed if estimated data were used when sample peak } \\
\text { areas exceeded calibration peak areas }\end{array}$ \\
\hline HRMS analysis & LRMS analysis & $\begin{array}{l}\text { LRMS analysis may cost between } 50 \text { and } 75 \% \text { of HRMS analysis due to less } \\
\text { expensive instrumentation }\end{array}$ \\
\hline HRMS analysis & TOC analysis & TOC analysis may cost as little as $5 \%$ of the HRMS analysis cost. \\
\hline
\end{tabular}


resulting in quicker turnaround times for results and more rapid decision-making while in the field.

Other modifications to traditional 1613B may provide costsavings with minimal impact on performance, but have not been evaluated in this study. Such modifications include use of alternative, fast GC columns that could reduce analysis time (Reiner et al., 2004; Patterson, 2003). These alternative options to traditional analyses should also be considered to give regulators beneficial and cost-effective choices in cleanup decisions.

\section{Conclusions}

In this comparison of analytical results for sediments and soils from 10 contaminated site locations, $\mathrm{TEQ}_{\mathrm{D} / \mathrm{F}}$ values generated using the alternate 1613B HRMS analysis method had strong linear correlation to the TEQ $\mathrm{D} / \mathrm{F}$ values generated using traditional EPA Method 1613B. This indicated that the alterations (use of PLE, not performing 2,3,7,8-TCDF second-column confirmation, extracting $<10 \mathrm{~g}$, and using estimated values when data exceeded the calibration) did not have a significant negative effect on the analytical results for this sample set. Additionally, greater than $90 \%$ of the alternate $1613 \mathrm{~B} \mathrm{TEQ}_{\mathrm{D} / \mathrm{F}}$ results fell in the same concentration intervals as they would have based on traditional EPA Method 1613B results. Substituting LRMS analysis for HRMS analysis of the same extracts also generated $\mathrm{TEQ}_{\mathrm{D} / \mathrm{F}}$ values with a strong linear correlation to EPA Method 1613B TEQ $_{D / F}$ values and resulted in similar placement within concentration interval categories. As an alternative screening approach, TOC, while an inexpensive analysis option, did not correlate well enough with $\mathrm{TEQ}_{\mathrm{D} / \mathrm{F}}$ to be a reliable indicator of $\mathrm{TEQ}_{\mathrm{D} / \mathrm{F}}$ concentrations.

When evaluating sediment and soil PCDD/F screening options, cost-saving laboratory-based alterations to traditional methods or less expensive techniques such as LRMS could be considered along with alternative technologies such as the bioanalytical technologies evaluated in the EPA SITE MMT Program. It should be noted that the equations presented in Table 3 were derived only with the intent to demonstrate correlation between analysis approaches and are not intended to create a model for converting results from a screening approach to traditional EPA Method 1613B results. When selecting alternative methods, consideration should be given to the effect the alternative method will have on determining TEQ or individual congeners and to the impact this would have on study objectives (i.e., what might be appropriate for screening a site might not be appropriate for risk assessments). In addition, while the samples used for the SITE MMT Program were dried and homogenized to minimize sample homogeneity as a variable in technology performance evaluation, real-world samples with high moisture content have the potential to add variability to results. Because of this, project sampling and data quality objective planning should allow for a subset of results from alternative methods to be verified with traditional methods.

\section{Acknowledgements}

The United States Environmental Protection Agency through its Office of Research and Development funded and managed the research described here under Contract No. EP-C-05-057 to Battelle Memorial Institute. It has been subjected to Agency review and approved for publication. The authors thank the Battelle staff responsible for sample homogenization, the alternate 1613B and LRMS analyses, and statistical analysis. Thanks to Axys Analytical
Services who provided the traditional EPA Method 1613B analyses and to Applied Marine Sciences who provided the TOC analysis.

\section{References}

Abad, E., Caixach, J., Rivera, J., 1997. Application of DB-5ms gas chromatography column for the complete assignment of 2,3,7,8-substituted polychlorodibenzo$p$-dioxins and polychlorodibenzofurans in samples from municipal waste incinerator emissions. Journal of Chromatography A 786, 125-134.

Brzuzy, L.P., Hites, R.A., 1995. Estimating the atmospheric deposition of polychlorinated dibenzo-p-dioxins and dibenzofurans from soils. Environmental Science \& Technology 29, 2090-2098.

van den Berg, M., Birnbaum, L., Bosveld, A.T.C., Brunström, B., Cook, P., Feeley, M. Giesy, J.P., Hanberg, A., Hasagawa, R., Kennedy, S.W., Kubiak, T., Larsen, J.C., van Leeuwen, F.X.R., Liem, A.K.D., Nolt, C., Peterson, R.E., Poellinger, L., Safe, S., Schrenk, D., Tillitt, D., Tysklind, M., Younes, M., Waern, F., Zacharewski, T., 1998. Toxic equivalency factors (TEFs) for PCBs, PCDDs, PCDFs, for humans and wildlife. Environmental Health Perspectives 106, 775-792.

van den Berg, M., Birnbaum, L., Denison, M., De Vito, M., Farland, W., Feeley, M., Fiedler, H., Hakansson, H., Hanberg, A., Haws, L., Rose, M., Safe, S., Schrenk, D., Tohyama, C., Tritscher, A., Tuomisto, J., Tysklind, M., Walker, N., Peterson, R., 2006. The 2005 World Health Organization reevaluation of human and mammalian toxic equivalency factors for dioxins and dioxin-like compounds. Toxicological Sciences 93 (2), 223-241.

De Rosa, C.T., Brown, D., Dhara, R., Garrett, W., Hansen, H., Holler, J., Jones, D., Jordan-Izaguirre, D., O'Conner, R., Pohl, H., Xintaras, C., 1997. Dioxin and dioxin-like compounds in soil, part 1: ATSDR interim policy guideline. Toxicology and Industrial Health 13 (6), 759-768.

Fraisse, D., Paisse, O., Nguyen Hong, L., Gonnard, M.F., 1994. Improvements in GC/MS strategies and methodologies for PCDD and PCDF analysis. Fresenius' Journal of Analytical Chemistry 348, 154-158.

Hölscher, K., Maulshagen, A., Shirkhan, H., Lieck, G., Behnisch, P., 2004. Automated rapid analysis for dioxin and PCBs in food, feeding stuff and environmental matrices. Organohalogen Compounds 66, 1-9.

Kitamura, K., Mochizuki, A., Choi, J., Takazawa, Y., Hashimoto, S., Ito, H., Fujimine, Y., Morita, M., 2004. Optimization of a method for determining dioxin in whole blood samples based on solvent extraction and simplified cleanup. Analyst 129, 315-322.

Li, W., Chen, Z.S., Li, C.Q., Huang, P., Liu, G.Y., Zhou, Z., 2003. Analysis of polychlorinated dibenzo-p-dioxins and polychlorinated dibenzofurans by the ASEHPLC method. Organohalogen Compounds 60, 9-12.

Misita, M., Schrock, M., Tracy, K., Tabor, J., 2003. Simultaneous extraction of PCDD/ PCDF and PCBs using accelerated solvent extraction for sediment, tissue, and sludge matrices. Organohalogen Compounds 60, 37-40.

NATO CCMS, 1988. International toxicity equivalency factors (I/TEF) method of risk assessment for complex mixtures of dioxins and related compounds, Report 178.

Patterson, D., 2003. History and current status of fast and sensitive analytical methods for measuring compounds of environmental concern at the centers for disease control and prevention. Organohalogen Compounds 60, 351-354.

Reiner, E., Boden, A., MacPherson, K., Kolic, T., Dorman, F., Cochran, J., 2004. Chromatographic enhancement techniques for the analysis of persistent organic pollutants in environmental samples. Organohalogen Compounds 66, 838-845.

Robinson, C., Blow, P., Dorman, F., 2004. Rapid dioxin analysis using accelerated solvent extraction (ASE), multi-column sample cleanup and Rtx-Dioxin2 gas chromatography column. Organohalogen Compounds 66, 1-6.

Sporring, S., Wiberg, K., Bjorklund, E., Haglund, P., 2003. Combined extraction/ clean-up strategies for fast determination of PCDD/Fs and WHO-PCBs in food and feed samples using accelerated solvent extraction. Organohalogen Compounds 60, 1-4

U.S. EPA, 1994. Method 1613, Revision B: tetra- through octa-chlorinated dioxins and furans by isotope dilution HRGC/HRMS, EPA/821/B-94-005.

U.S. EPA, 1996. SW-846 method 8280A: the analysis of polychlorinated dibenzo$p$-dioxins and polychlorinated dibenzofurans by high resolution gas chromatography/low resolution mass spectrometry (HRGC/LRMS), Revision 1.

U.S. EPA, 2004a. Demonstration and quality assurance project plan, EPA/600/R-04/ 036

U.S. EPA, 2004b. SW-846 method 9060A: total organic carbon, Revision 1.

U.S. EPA, 2005a. Innovative technology verification report, Xenobiotic Detection Systems, CALUX ${ }^{\circledR}$ by XDS, EPA/540/R-05/001

U.S. EPA, 2005b. Innovative technology verification report, Wako Pure Chemical Industries, Dioxin ELISA Kit, EPA/540/R-05/002.

U.S. EPA, 2005c. Innovative technology verification report, Abraxis, coplanar PCB, ELISA Kit, EPA/540/R-05/003.

U.S. EPA, 2005d. Innovative technology verification report, Cape Technologies, DF1 dioxin/furan immunoassay kit and PCB TEQ immunoassay kit, EPA/540/R-05/ 004

U.S. EPA, 2005e. Innovative technology verification report, Hybrizyme Corporation, AhRC PCR ${ }^{\mathrm{TM}}$ Kit, EPA/540/R-05/005. 